\title{
HIV-infected individuals who delay, decline, or discontinue antiretroviral therapy: comparing clinic- and peer-recruited cohorts
}

\section{Marya Gwadz ${ }^{1}$, Elizabeth Applegate ${ }^{1}$, Charles Cleland ${ }^{1}$, Noelle Regina Leonard ${ }^{1}$, Hannah Wolfe ${ }^{2}$, Nadim Salomon ${ }^{3}$, Mindy Belkin ${ }^{1}$, Marion Riedel ${ }^{4}$, Angela Banfield ${ }^{1}$, Lisa Sanfilippo ${ }^{1}$, Andrea Wagner ${ }^{1}$, Donna Mildvan ${ }^{5}$ and The Heart to Heart Collaborative Research Team}

\author{
Center for Drug Use and HIV Research (CDUHR), New York University, College of Nursing, New York, NY, USA \\ ${ }^{2}$ Spencer Cox Center for Health, Mount Sinai St. Luke's-Roosevelt Hospital Center, New York, NY, USA \\ ${ }^{3}$ Peter Kruger Clinic, Mount Sinai Beth Israel Medical Center, New York, NY, USA \\ ${ }^{4}$ School of Social Work, Columbia University, New York, NY, USA \\ ${ }^{5}$ Department of Infectious Diseases, Mount Sinai Beth Israel Medical Center, New York, NY, USA
}

\section{Edited by:}

Maria Prins, Public Health Service of Amsterdam, Netherlands

Reviewed by:

Anthony Jaworowski, Burnet Institute, Australia

Arjan E. R. Bos, Open University of the Netherlands, Netherlands

*Correspondence:

Marya Gwadz, New York University College of Nursing, 726 Broadway,

10th Floor, New York, NY 10003, USA e-mail:mg2890@nyu.edu
A substantial proportion of persons living with HIVIAIDS (PLHA) delay, decline, or discontinue antiretroviral therapy (ART) when it is medically indicated (40-45\%), largely African-Americans and Latinos/Hispanics. This study explores the feasibility of locating PLHA, who are not on ART (PLHA-NOA) through clinics and peer-referral; compares the two cohorts on multi-level barriers to ART; and examines readiness to initiate/reinitiate $A R T$, a predictor of treatment outcomes. We recruited adult HIV-infected African-American and Latino/Hispanic PLHA-NOA through HIV hospital clinics and peer-referral in 2012-2013. Participants were engaged in structured 1-h assessments with reliable/valid measures on barriers to ART. We found that recruitment through peers $(63.2 \%, 60 / 95)$ was more feasible than in clinics $(36.8 \%, 35 / 90)$. Participants were 48.0 years old and had lived with HIV for 14.7 years on average, and $56.8 \%$ had taken ART previously. Most (61.1\%) were male and African-American (76.8\%), and 23.2\% were Latino/Hispanic. Peer-recruited participants were older, had lived with HIV longer, were less engaged in HIV care, and were more likely to have taken ART previously. The cohorts differed in reasons for discontinuing ART. Levels of ART knowledge were comparable between cohorts (68.5\% correct), and there were no differences in attitudes toward ART (e.g., mistrust), which were in the neutral range. In bivariate linear regression, readiness for ART was negatively associated with physician mistrust $(B=-10.4)$ and positively associated with self-efficacy $(B=5.5)$, positive outcome expectancies ( $B=6.3$ ), beliefs about personal necessity of ART ( $B=17.5$ ), and positive internal norms $(B=7.9)$. This study demonstrates the feasibility of engaging this vulnerable population through peer-referral. Peer-recruited PLHA evidence particularly high rates of risk factors compared to those in hospital clinics. Interventions to support ART initiation and continuation are sorely needed for both subgroups.

Keywords: HIV, barriers, antiretroviral, African-American, Latino, discontinue, delay, decline

\section{INTRODUCTION}

The proportion of persons living with HIV/AIDS (PLHA) who initiate antiretroviral therapy (ART) in a timely fashion has increased in recent decades $(1,2)$. Yet a substantial proportion of PLHA is not taking ART when it is medically indicated, because they decline or delay ART when it is offered, discontinue ART, or do not otherwise have good access to ART regimens $(3,4)$. We refer to this population of PLHA not on ART when it is medically indicated as "PLHA-NOA." The individual, community, and societal-level consequences of PLHA not gaining access to ART are grave, and include high rates of morbidity, reduced quality of life, earlier mortality, viral resistance (when ART is discontinued), increased risk of transmission of HIV to others, and high health care costs (5-9).

Studies characterizing rates of diagnosis with HIV, linkage to and retention in care, ART uptake, and viral suppression, called the "HIV continuum of care" or "treatment cascade," highlight the very serious problem of PLHA-NOA. A 2012 Centers for Disease Control and Prevention (CDC) report described a number of gaps: of the 1.1 million Americans living with HIV, 63\% are not retained in care; $67 \%$ have not been prescribed ART, and only one-quarter have suppressed viral load (3). Based on these CDC data, we conservatively estimate that $40-50 \%$ of PLHA in the US have unmet need for ART, mainly those who are also not well engaged in care. These high estimates of PLHA-NOA are supported by data on ART discontinuation, where up to $40-50 \%$ of those who initiate ART discontinue their regimens at least once within a year (10-12).

The majority of PLHA in the US are from African-American and Latino/Hispanic backgrounds (approximately 60\%), and likewise, the majority of PLHA-NOA is from racial/ethnic minority backgrounds $(3,13)$. Indeed, the racial and ethnic background of 
PLHA-NOA is relevant because barriers to ART tend to vary across racial/ethnic groups, and interventions to reduce barriers to health can be culturally targeted to the factors with the greatest relevance to various subgroups of PLHA $(14,15)$.

In contrast to the large literature on ART adherence, little is known about the factors that drive the problem of PLHA-NOA. In the next section, we consider factors believed to contribute to discontinuation, delay, and decline of ART, and poor access to ART. In light of the complexity of the problem of PLHA-NOA, the present study was guided by the theory of triadic influence, a multi-level social-cognitive theory that examines three "streams of influence" on health behavior: individual/attitudinal, social, and structural (16).

At the individual/attitudinal level of influence, poor understanding of HIV treatment as well as misconceptions about ART appears to contribute to PLHA-NOA(17). PLHA may not perceive the need for ART, particularly when they feel healthy (18). AfricanAmerican and Latino/Hispanic PLHA evidence a number of HIVand health care-related attitudes and beliefs rooted in culture and U.S. history. Specifically, these beliefs are partly grounded in the history of past abuses of people from racial/ethnic minority backgrounds by medical research, the medical establishment, and larger society, which have been described as resonating with present-day exclusion, discrimination, and structural racism (13, 19-21). The Tuskegee Syphilis study is perhaps the most emblematic example of past abuses, and this and other examples of maltreatment contribute to fear and distrust, not only of ART, but also the HIV care system, health care providers, and other larger societal structures $(22,23)$. Further, negative perceptions of ART, particularly fear of side effects, are common and can impede acceptance of ART (2426), as do negative outcome expectancies, that is, the belief ART is ineffective and/or toxic (26). Moreover, low self-efficacy for managing and adhering to $\operatorname{ART}$ may reduce $\operatorname{ART}$ initiation $(24,25,27)$. These attitudes and intentions appear to interact to contribute to a belief that ART is unnecessary or even harmful that it cannot be tolerated or successfully managed, and/or create fears that one is not "ready" to manage an ART regimen $(24,28)$. Indeed, a number of studies have argued that readiness for ART is an important latent construct that influences both adherence and treatment outcomes, which can therefore be targeted in behavioral interventions to improve ART outcomes $(29,30)$. Yet fears and negative health beliefs do not preclude interest in ART or even ART initiation. PLHA, including those from racial/ethnic minority backgrounds, can simultaneously evidence curiosity about and willingness to initiate treatment options, along with fear and negative health beliefs $(31,32)$.

Persons living with HIV/AIDS' health status can impede uptake of ART. PLHA face challenges accessing HIV health care $(3,33)$ and sub-optimal engagement in care is common $(3,5)$. Those attending fewer health care visits are less likely to initiate ART (34), suggesting that those with poor access to care are less likely to use ART, those who do not wish to initiate ART elect to attend fewer health care appointments in order to avoid such discussions with providers, and that barriers to ART also impede access to care (35). Moreover "competing priorities" interfere with initiation of ART, primary among them are alcohol and non-injection drug use problems $(36,37)$, injection drug use in some studies, mental health symptoms, and unstable housing (17, 27, 38-40). Yet competing priorities, while serious, do not necessarily preclude individuals from initiating and sustaining ART with high adherence. Past studies have shown these types of barriers can be ameliorated through interventions, and that among populations with competing priorities, rates of ART initiation with high adherence improve with clinical care, behavioral interventions, and support (36).

Social-level barriers include fear of HIV-related stigma that might arise if others were aware of their HIV diagnosis. Moreover, PLHA who perceive negative peer norms regarding ART, that is, that their peers tend to avoid ART or view ART negatively, or would view the PLHA negatively if he/she took ART, may be less likely to initiate and sustain these regimens $(41,42)$. PLHA's relationships with health care providers play a critical role in ART initiation. National HIV treatment guidelines recommend that providers evaluate and manage factors that might impede adherence to ART (43). Yet some studies suggest that providers may delay recommending ART to patients because of concerns that patients will be unable to benefit from or adhere to ART $(4,25$, $26,44)$. Wong and colleagues (4) found that African-Americans initiate ART later than Whites regardless of providers' attitude toward prescribing ART, but that provider beliefs led to delayed prescribing of ART to Latinos/Hispanics, women, and those with low socioeconomic status (4). The problem of PLHA-NOA is complicated by the fact that some patients are hesitant to tell their providers that they are not taking ART, for example in cases when providers have prescribed ART and assume patients have initiated it (45).

Structural barriers are features of the external environment (economic, geographic, policy, organizational or other) that limit individuals' options (46). Aspects of the HIV care setting including its location, structure, policies, and quality of care can promote or impede access to ART $(47,48)$. While few studies have compared the initiation of ART, adherence, or retention in care between patients in comprehensive hospital HIV clinics vs. those in community care settings, recent work suggests that rates of initiation of ART are similar between the two settings, although communitybased clinics may see patients earlier in their HIV disease as a result of outreach efforts $(49,50)$. Yet another recent study suggests that patients in community-based clinics have better health care retention but those in hospital-based clinics are more likely to be virally suppressed (51). Thus the setting where PLHA receive care may influence patterns of ART initiation. A second structural barrier to ART may be the short health care encounter, which is not well designed to overcome multiple, intersecting barriers to ART (40). Last, in some locations, vulnerable PLHA are offered the chance to sell medications back to a pharmacy, an illegal activity that thereby decreases uptake of ART (51).

The HIV continuum of care models indicate that PLHA-NOA can be found in clinic settings (3). Yet little is known about strategies to seek out PLHA-NOA who do not regularly attend clinic visits. Because PLHA tend to be socially linked (52), peer-recruitment methods may hold promise for seeking out and engaging PLHANOA, including those with less frequent involvement in care (52, 53 ). Thus one aim of the present study was to explore the feasibility of both clinic- and peer-based strategies for locating and engaging 
PLHA-NOA into a research study on barriers to ART initiation and continuation.

This is an exploratory study of an under-studied population, PLHA-NOA, focused on the population of African-American and Latino/Hispanic individuals PLHA who comprise the majority of this vulnerable group. The aims of the study were to extend past research on PLHA-NOA that has focused mainly on clinic settings and (1) explore the feasibility of recruiting PLHA-NOA from HIV hospital clinics compared to peer-referral, and gain insights to refine recruitment procedures for future research; (2) describe the clinic and peer-recruited cohorts and compare them with respect to socio-demographic, background, and health characteristics, including reasons for delaying/declining or discontinuing ART, as appropriate; (3) compare individual/attitudinal-, social, structural-level factors hypothesized to impede ART initiation between the two groups; (4) identify factors that predict "readiness" to initiate ART, including whether cohort (clinic vs. peerrecruited) and past use of ART are associated with readiness to initiate ART; and (5) explore whether those who have taken ART in the past differ from those who have never taken ART on background, health, and other factors. We hypothesized that it would be more feasible to locate and engage PLHA-NOA in clinic settings than through peers, because they have a prior connection to the setting, which could facilitate linkage to the study. Because little is known about the barriers to ART for PLHA-NOA, we do not present hypotheses regarding how clinic and peer-recruited cohorts may differ with respect to these factors.

\section{MATERIALS AND METHODS}

Participants were 95 individuals recruited in HIV hospital clinics $(N=35)$ and through peer-referral $(N=60)$, who were medically eligible for ART but not taking ART, as part of an intervention development study on increasing ART initiation in this group. The clinic-recruitment study component was located in two large hospital-based HIV clinics in New York City, each serving between 1000 and -4000 PLHA, primarily those from African-American and Latino/Hispanic backgrounds, where prior to the study an estimated $10 \%$ of the patient population had delayed, declined, or stopped ART when it was medically indicated. The peer-referral component, described below, was located at a project field site. Recruitment procedures for the two cohorts differed in a modest number of respects, as we describe below, although eligibility criteria were the same. Procedures were approved by the Institutional Review Boards at the two collaborating hospitals and New York University.

\section{RATIONALE FOR STRUCTURE OF PROCEDURES}

As described above (see Introduction), PLHA-NOA experience numerous barriers to ART. As a result, PLHA may not fill ART prescriptions written for them, may fill them but not take ART, may sell ART to a pharmacy, or may stop taking ART, but may not feel comfortable disclosing their ART decisions to providers (45). Thus, although providers generally discuss ART with patients and monitor clinical indicators of treatment effects at regular intervals - assuming patients present for care - providers may not know for certain if an individual is taking ART. This complicates efforts to determine whether an individual is taking ART for the purposes of research: participants may be motivated to obscure the fact that they are actually taking ART to enroll in the study, and on the other hand, participants who are not taking ART may be hesitant to disclose this fact, particularly in cases where the provider believes they are taking ART. Thus, in light of potentially conflicting information from providers, the medical record, and patients, in at least a minority of cases, procedures were developed to attempt to tease out which patients were not on ART and who therefore met this study inclusion criterion, as we describe below (see Figure 1).

\section{RECRUITMENT AND ENROLLMENT \\ Clinic sample}

Extraction of health information from the medical record. From the medical record, the HIV clinics identified participants (1) aged 18 years or older, (2) African-American or Latino/Hispanic, (3) HIV infected for $\geq 6$ months, (4) medically eligible for ART for $\geq 3$ months, (5) had seen a provider at the clinic at least once in the past year, (6) last CD4 count $<500$ cells/mL, (7) able to conduct research activities in English, and (8) with indications that the patient may not be taking ART including (a) medical record indicates patient is not on ART (e.g., ART refused, ART not prescribed) or (b) patient has been prescribed ART for at least 3 months but has detectable viral load (>1000 copies/ppmL), and (9) patient does not have any condition that in the opinion of the primary care provider would interfere with provision of informed consent or make it unsafe for the patient to participate in this study. Patients meeting these criteria were included on a "recruitment roster." Determination of ART status (i.e., never took ART or took ART in the past but on fewer than 60 days in the past 6 months and not at all in the past 30 days) tool place in a subsequent step, as described in the next section.

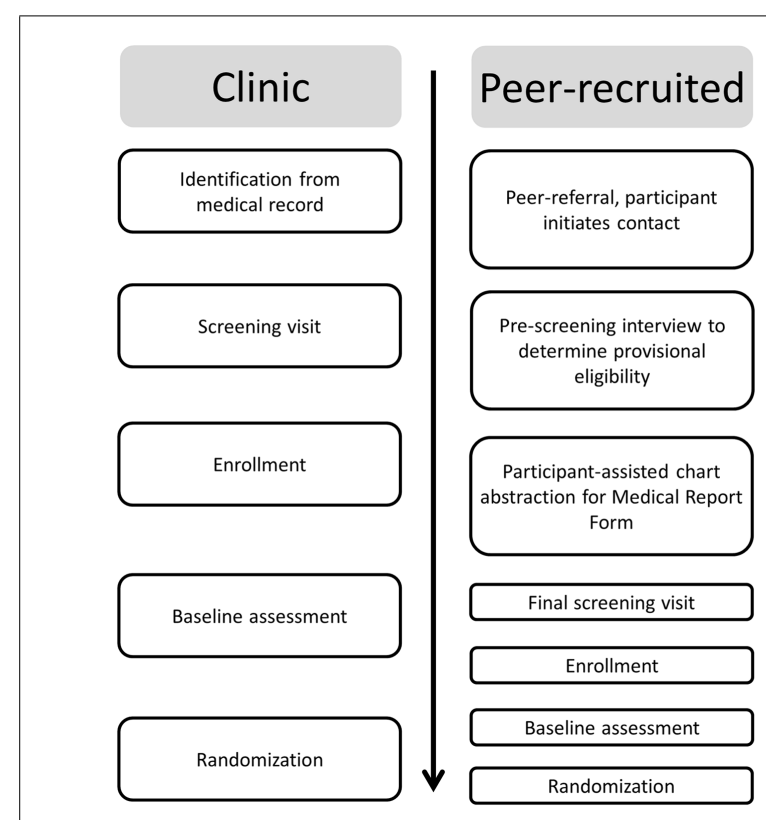

FIGURE 1 | Enrollment procedures. 
Screening visit. Patients on the recruitment roster were either met in person at the time of their next clinic appointment or contacted by phone by a clinic staff member (depending on the policies of the clinic), and invited to a screening visit, called a "health check up" (HCU). Participants gave signed informed consent before participating in the screening visit. The screening visit had two main goals: (1) engagement and relationship building and (2) evaluation of ART status to determine whether the patient was eligible for the study. The screening interview alternated between structured assessment instrument segments using the computerassisted personal interview format (CAPI), and open discussion of pre-specified questions health and ART issues. Thus we also collected other demographic and health information, which were included in the research record if the patient enrolled in the study. The open-ended discussion component was guided by the motivational interviewing approach (54) to encourage frank discussion of sensitive subjects (e.g., medication selling, having stopped ART but not yet having told the provider), to convey respect for autonomy, and reduce fear and social-desirability bias (54). With respect to the ART inclusion criterion, participants were coded as (10a) never took ART; (10b) took ART in the past but not in the past 6 months; (10c) took ART in the past but on fewer than 60 days in the past 6 months and not at all in the past 30 days (because PLHA may initiate ART but stop after a brief period); and (10d) took ART on more than 60 days in the past 6 months or took ART in the past month. Those in categories $10 \mathrm{a}-10 \mathrm{c}$ were eligible for the study and those coded as category 10d were ineligible and were referred to adherence counseling or their provider, as appropriate. Those found eligible based on all inclusion criteria assessed from the medical record, provider, and this screening interview were then invited to participate in the larger research study. The screening visit took place at the HIV clinic sites. Participants received compensation of $\$ 30$ plus funds for local transportation for this visit. In keeping with the exploratory nature of the study, when the medical record and participants' reports were discrepant with respect to ART initiation (namely, the participant stated that he/she was not taking ART but the provider or medical record indicated he/she most likely had initiated it), participants were enrolled into the study. Participants gave consent for data from the medical record data, which were recorded on a Medical Report Form, to be included in the research record. Otherwise, they were destroyed.

Study enrollment and baseline assessment. After providing signed informed consent for remaining study activities, participants found eligible for the study engaged in a structured baseline assessment on HIV knowledge, a range of attitudes toward and beliefs about ART, and health care use patterns on a computer, lasting approximately $1 \mathrm{~h}$. The assessment was conducted in both computer-assisted audio interviewing (CAPI) and audio, computer-assisted self-interviewing (ACASI) formats. Assessments took place at the HIV clinics. Participants received \$20 and fare for local public transportation for their time. Clinic- and peer-recruited participants completed the same set of measures, which focused on the lifetime and past 6 months. The amount of time to enroll participants into the clinic-recruited cohort was 3-6 weeks, with participants typically being enrolled within 4 weeks.

\section{Peer-recruited cohort}

Peer sampling method. Participants were recruited using a chainreferral peer sampling method (53). Initial recruiters $(N=88)$ were drawn from a pre-existing recruitment registry of HIVinfected individuals maintained by the research study team. Individuals in the recruitment registry who met inclusion criteria were also eligible for the study ( $N=9$ enrolled). We also provided other peer-recruited study participants with the opportunity to recruit their own peers. Recruiters were given up to 10 coded recruitment coupons and instructed to provide these coupons to HIV-infected individuals who they knew by name or face, who may not be on ART or engaged in health care (a proxy for delaying, declining, or discontinuing ART). To protect confidentiality, peers contacted the study directly to be screened for eligibility. Recruiters received compensation of $\$ 10$ for each peer who contacted the study and was screened. We also accepted direct referrals from participants who had heard about the study in the community, and recruited directly at number of community-based organizations. The order of study activities for the peer-recruitment cohort differed in some respects from those described above, because we did not have a pre-established relationship with the health care providers of these participants, and did not have access to their medical records at the time the participant presented to the study, as we describe below.

\section{Brief pre-screening health interview to determine provisional eli-} gibility. Peer-referred individuals contacted the study, and were scheduled for a brief pre-screening health interview conducted in person at a project field site. Participants gave verbal informed consent for this activity. Inclusion criteria for this first stage of eligibility included (1) aged 18 years or older, (2) African-American or Latino/Hispanic, (3) HIV infected for $\geq 6$ months, (4) able to conduct research activities in English, (5a) never took ART or (5b) took ART in the past but on fewer than 60 days in the past 6 months and not at all in the past 30 days. To meet the CD4 criterion we assessed whether (6a) last CD $4 \leq 500$ cells/mL or $(6 \mathrm{~b})$ the participant had not had CD4 tested in past year or (6c) he/she did not know his/her CD4 count. These criteria were assessed by self-report and were later confirmed by the medical record where possible. HIV status was confirmed with medical documentation prior to enrollment (examples include test results from a lab or testing site, local HIV benefits eligibility card). Participants who meet these criteria were provisionally eligible to enroll in the study. They received compensation of \$15 and fare for local transportation for this brief interview.

Participant-assisted chart abstraction for medical report form. As noted above (see Extraction of health information from the medical record), two inclusion criteria are reported by the participant's health care provider (\#4 - medically eligible for ART for $\geq 3$ months; $\# 9$ - whether the patient had any condition that would interfere with provision of informed consent or make it unsafe). Peer-recruited participants provisionally eligible at screening provided signed informed consent for the project to have the health care provider complete a Medical Report Form with these and other inclusion criteria drawn from the medical record. Alternately, participants could ask the provider themselves to complete the form. Participants received compensation of \$15 for having the 
Medical Report Form completed. In keeping with the exploratory nature of the present study, participants not linked to health care (defined as not engaging in any HIV-related health care visits in past year) could remain in the study, and were referred to HIV care during the study.

Screening visit to establish eligibility. As described above (see Screening visit), participants engaged in a screening visit with structured and open-ended components to determine eligibility with respect to ART status. Participants received compensation of $\$ 30$ for this session, plus fare for local transportation.

Enrollment and assessment. Participants who met the inclusion criteria provided signed informed consent to be enrolled in the study, and participated in the structured baseline interview as described above (see Study enrollment and baseline assessment). The amount of time to enroll participants into the peer-recruited cohort was 1-8 weeks, with participants typically being enrolled within 6 weeks.

\section{MEASURES}

\section{Socio-demographic, background, and health characteristics}

We assessed socio-demographic characteristics such as age, sex, race/ethnicity, sexual minority status, and employment status with a structured measure (55). We assessed HIV history including year of first HIV diagnosis, time between diagnosis and engagement in health care, current health status (at a level of good or better), nadir and most recent CD4 levels, most recent viral load levels, and ART history with a measure from the HIV cost and services utilization study (HCSUS) (56). HIV-related symptoms were assessed with the symptoms distress module (57). The module uses a five-point scale, which is summed to characterize the extent of symptom distress experienced (Cronbach's $\alpha=0.87$ ). HIV care utilization in the past 6 months was assessed with items from the service utilization battery (58). We assessed 11 reasons for discontinuing ART using a scale developed by Johnson and colleagues (yes/no) (18).

\section{Individual/attitudinal influences}

HIV treatment knowledge. Treatment knowledge was assessed on a reliable 14-item three-point scale (true, false, and not sure, Cronbach's $\alpha=0.76)$. Treatment knowledge was scored as the number of items answered correctly (range 0-14) (59).

Mistrust. General medical mistrust, that is, mistrust of the healthcare system in general, was assessed with a seven-item assessment using a five-point Likert-type scale (strongly disagree to strongly agree) (Cronbach's $\alpha=0.72$ ). After reverse coding of one item, the total score was the average across the items, which ranged from 0 to 4 , with a higher number indicating greater mistrust (60). HIV and ART mistrust was assessed with a reliable (Cronbach's $\alpha=0.84$ ) 10 -item measure that assesses attitudes toward healthcare organizations that provide HIV care and HIV medication on a five-point Likert-type scale (strongly disagree to strongly agree) (61). After reverse coding of two items, the total score was the average across items, which ranged from 0 to 4 , with a higher number indicating greater mistrust. Mistrust in one's health care provider was assessed by the trust in physician scale (62), an 11-item measure assessing measuring dependability, confidence, and confidentiality of information on a five-point Likert-type scale (strongly disagree to strongly agree) (Cronbach's $\alpha=0.88$ ). All items were coded such that a higher number indicated greater mistrust. The total score was the average across items, which ranged from 0 to 4 .

ART health beliefs. Antiretroviral therapy taking self-efficacy was assessed with a 17-item highly reliable measure that uses a 10-point Likert scale, with higher scores indicating greater HIV medication-taking self-efficacy (Cronbach's $\alpha=0.95$ ) (63). ART outcome expectancies, in this case, are the participant's confidence that ART will have beneficial health and quality of life outcomes if taken, were assessed on a nine-item measure that uses a 10point Likert scale with higher scores indicating more positive ART outcome expectancies (Cronbach's $\alpha=0.95$ ) (63). Further, the beliefs about medication questionnaire (BMQ) (64) is a 13 item scale comprising two subscales measuring beliefs about medications, revised to assess beliefs about ART: personal necessity for ART (e.g., my health in the future will depend on these medications, Cronbach's $\alpha=0.88$ ) and concern/fear about effects of ART (e.g., the idea of taking HIV medications worries me, Cronbach's $\alpha=0.68$ ). Participants indicate that the degree of agreement with individual statements about ART on a five-point Likert scale ranges from $1=$ strongly disagree to $5=$ strongly agree. Scores obtained for the individual items within each scale are summed to give a scale score.

"Readiness" to take ART. "Readiness" to take ART at the present time was assessed using two items, modeled on the approach developed by Rollnick (65): the perceived importance of taking ART and confidence that he/she could take HIV medication every day, as prescribed, if he/she so desired (65). Both were assessed on a 0-10 scale and these two ratings were multiplied to create the "readiness" variable, leading to a range from 0 to 100, where higher scores indicate greater readiness for ART.

\section{Social factors}

ART-related stigma. Concern about stigma associated with ART was assessed with three items drawn from the Patient Medication Adherence Questionnaire (66) (e.g., I don't want people to see me take my HIV medicines), assessed on a three-point scale (disagree, not sure, and agree). Each item was scored from 1 to 3 , and the total score was the average across items, with a higher score indicating greater stigma (Cronbach's $\alpha=0.73$ ).

Social norms supportive of ART. Egocentric social norms supportive of ART were assessed using a single item tapping into the extent to which social network members living with HIV are perceived as favorable toward or currently taking ART using a seven-point Likert-type scale ranging from none to almost all social network members (how many of the people you know who are living with HIV or AIDS would consider taking HIV medication?) (67). External injunctive social norms, the extent to which participants perceive close friends and family as encouraging or supporting the participant to take ART, were assessed with a single item using a seven-point Likert-type scale ranging from none to almost all social network members (how many of your close 
friends and family would support you if you started HIV medication?) (67). Internal norms supportive of ART (how you feel about things others may do?) were assessed with a single item using a four-point Likert-type scale (strongly disagree to strongly agree) that was reverse coded (I think people who take HIV medications are making a mistake.) (67).

\section{Structural factors}

Received care in a hospital clinic. Using a single item we assessed whether participants received care in a hospital HIV clinic, which tend to be larger and provide a comprehensive set of high-quality health, mental health, and social services, vs. other settings (private practice, community setting, and emergency room).

Satisfaction with health care. Satisfaction with health care was assessed with the Client Satisfaction Survey (68), a four-item measure that uses a four-point Likert scale. Individual items were scored from 0 to 3 , with higher numbers indicating greater satisfaction. The total score was the average across items (Cronbach's $\alpha=0.85$ ). Satisfaction with care could be considered an individual/attitudinal-level variable, but was used as a proxy for setting quality in this study.

Selling ART. Participants were asked, "People have told us that in tough times, they have sold their HIV medication to others in order to pay for necessities. In your whole life, have you ever had to sell your HIV medications?" Participants were also asked if they had sold ART over the past 6 months. Both items were scored as yes/no.

\section{MISSING DATA}

Missing data were handled by the multiple imputation method, which is more powerful and less biased than ad hoc methods of handling missingness (e.g., listwise deletion). This approach assumes that data are missing at random (MAR), that is, MAR conditional on values observed. Missing data were imputed 100 times using a chained equation approach (69), as implemented by the R Core Team (70) MICE package (71). Estimates and standard errors from complete-data analyses of these 100 imputed datasets were combined into a single inference (point estimate, standard error, and confidence interval) using the approach described by Rubin (72). Details on the extent of missing data are provided in the tables. The variables with the largest percentage of missing data included medical records-based viral load (52\%) and CD4 (36\%), which we were unable to obtain from health care providers or medical institutions for some in the peer-recruited cohort. Across all other study variables, less than half of all variables had any missing data, and data were missing for at most $8 \%$ of participants (the "egocentric norms supportive of ART" measure).

\section{DATA ANALYSIS}

Bivariate linear regression was used to estimate associations between potential predictors and ART readiness. Then, multiple regression analysis was used to examine, among the variables with a significant bivariate association with ART readiness, which variables also had a significant unique association with ART readiness. The $R$ statistical computing environment was used for all analyses (70).

\section{RESULTS \\ FEASIBILITY OF ENROLLING IN CLINICS AND THROUGH PEER-REFERRAL \\ Clinic cohort}

The total number of patients at the two HIV clinics was 4758, of which 206 (4.3\% of the clinic population) were not on ART and 148 met preliminary eligibility criteria. These 148 individuals (3.1\% of the clinic population) were targeted for screening and, if eligible, enrolled. Of these, we were unable to contact 99 (66.9\%), often because participants did not present for appointments at the scheduled times and we were therefore unable to recruit them. Further, eight individuals declined to participate (5.4\%), providers did not approve participation in six cases $(4.1 \%)$; and eight were found to be ineligible in the screening meeting $(5.4 \%)$. A total of 35 (23.7\% of the 148 found preliminarily eligible) were found eligible and were enrolled.

\section{Peer-recruited cohort}

A total of 135 were pre-screened through peer-referral $(N=108)$, the recruitment registry $(N=15)$, and directly recruitment from community-based organizations $(N=12)$. Most $(N=119$; $88.2 \%$ ) were found preliminarily eligible based on self-report data. Next, of these 119 potential participants, we obtained medical report forms to confirm inclusion criteria from 55 participants $(46.2 \%)$. We found that 26 were ineligible $(N=22, \mathrm{CD} 4>500$; $N=3$ provider reported patients was taking ART and patient confirmed in the screening meeting; $N=1$ provider did not consent to patient participating). The remaining 29 were found eligible $(N=11$ provider reported the patient was on ART but the patient reported not taking it; $N=8$ provider was unsure if the patient was taking ART; $N=10$ provider reported patient was not on ART). For 34, the medical report form was waived because the participant reported not having seen a health care provider in the past year. A total of 60 peer-recruited participants were enrolled, $50.4 \%$ of the 119 found preliminarily eligible.

\section{SOCIO-DEMOGRAPHIC AND HEALTH CHARACTERISTICS}

Socio-demographic and other characteristics of the sample are described in Table 1. Approximately $60 \%$ of the sample was male and the mean age was 48.2 years ( $\mathrm{SD}=8.88$ years). More than two-thirds $(76.8 \%)$ of participants were African-American, and the remainder was Latino/Hispanic (23.2\%). More than a third (39.0\%) was a "sexual minority" (lesbian, gay, or bisexual). Few were currently employed (16.8\%), but most had a high school diploma or equivalent $(66.3 \%)$. Those in the peer-recruited cohort were significantly older and less likely to be employed, but did not differ from their clinic-recruited peers on other socio-demographic characteristics. Participants had been diagnosed with HIV for 14.7 years on average ( $S D=8.73$ years). At first diagnosis, $40 \%$ had delayed entering care for more than 6 months. The most recent CD4 count from the medical report forms was 302.8 cells $/ \mathrm{mL}$ on average $(\mathrm{SD}=138.9$ cells $/ \mathrm{mL})$ and $\log _{10}$ viral load was 3.49 ( $\mathrm{SD}=1.36)$. Self-reported $\mathrm{CD} 4$ were comparable to the medical record data: 343.06 cells $/ \mathrm{mL}(\mathrm{SD}=128.57$ cells $/ \mathrm{mL})$, as was viral load. About half (56.8\%) had taken ART in the past. Almost all (99.0\%) reported that their provider had recommended that they take ART over their lifetimes. About three-quarters 
Table 1 | Socio-demographic, background, and health characteristics

\begin{tabular}{|c|c|c|c|c|}
\hline & $\begin{array}{l}\text { Clinic }(N=35) \\
\text { Mean }(S D) / \%\end{array}$ & $\begin{array}{l}\text { Peer-referred }(N=60) \\
\text { Mean }(S D) / \%\end{array}$ & $\begin{array}{l}\text { Total }(N=95) \\
\text { Mean }(S D) / \%\end{array}$ & $\boldsymbol{p}$ \\
\hline Age in years & $44.8(10.8)$ & $49.9(7.0)$ & $48.0(8.9)$ & * \\
\hline Male sex & 65.7 & 58.3 & 61.1 & \\
\hline African-American, not Latino/Hispanic & 71.4 & 80.0 & 76.8 & \\
\hline Latino/Hispanic & 28.6 & 20.0 & 23.2 & \\
\hline Sexual minority status (gay, lesbian, and bisexual) & 48.6 & 33.3 & 39.0 & \\
\hline Currently employed & 28.6 & 10.0 & 16.8 & * \\
\hline \multicolumn{5}{|l|}{ HEALTH } \\
\hline Years since HIV diagnosis (self-report) & $12.1(9.1)$ & $16.13(8.2)$ & $14.65(8.7)$ & * \\
\hline >6 months between HIV diagnosis and care appointment & 25.7 & 48.3 & 40.0 & * \\
\hline Health self-rating "good" or better & 77.1 & 61.7 & 67.4 & \\
\hline CD4 nadir/lowest CD4 cell count ever & $246.0(142.4)$ & $136.6(116.6)$ & $173.6(135.3)$ & ** \\
\hline Most recent CD4 (medical report form) & $344.8(128.6)$ & $249.9(135.4)$ & 302.8 (138.9) & ** \\
\hline Most recent CD4 (self-report) & $343.1(127.1)$ & $254.3(143.4)$ & $291.7(143.0)$ & ** \\
\hline Most recent $\log _{10}$ viral load (medical report form) & $3.9(0.9)$ & $2.9(1.7)$ & $3.5(1.4)$ & * \\
\hline Most recent $\log _{10}$ viral load (self-report) & $3.9(1.1)$ & $3.2(1.5)$ & $3.4(1.4)$ & * \\
\hline Health care provider recommended ART (lifetime) & 100.0 & 98.3 & 99.0 & \\
\hline Medical provider knows not taking HIV medications at this time & 100.0 & 88.3 & 92.6 & * \\
\hline$>1$ HIV health care appointments in the past 6 months & 88.6 & 61.7 & 71.6 & ** \\
\hline Symptoms distress module (0-72) & $16.9(15.8)$ & $18.7(13.7)$ & $18.0(14.5)$ & \\
\hline Ever taken ART & 42.9 & 65.0 & 56.8 & $\S$ \\
\hline
\end{tabular}

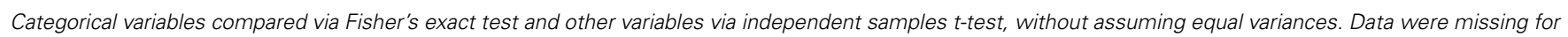

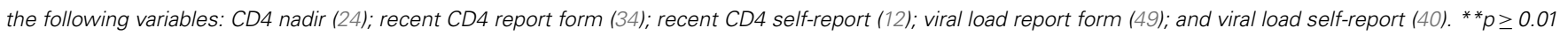
level, ${ }^{*} p \geq 0.05$ level, ${ }^{5} p \geq 0.10$ level.

(71.6\%) had attended one or more HIV care appointments in the past 6 months. Rates of HIV-related symptoms were modest on average ( 18.03 on average on a $0-72$ scale; $\mathrm{SD}=14.46$ ). Compared to their clinic-recruited peers, the peer-recruited cohort exhibited worse health outcomes on almost every index, as shown in Table 1.

\section{REASONS FOR ART DISCONTINUATION}

As presented in Table 2, among those who had taken ART previously, the main reasons for participants' discontinuing ART in the past were side effects $(68.6 \%)$, "changed my mind" $(62.0 \%)$, "life circumstances changed" (54.9\%), difficulties with adherence $(47.1 \%)$, substance use got in the way $(45.1 \%)$, and "was not ready" (39.2\%). About half (52.9\%) reported other reasons for discontinuing ART in an open item question, which included the following: ART was taken only during pregnancy and the participant did not wish to continue, difficulty swallowing or dislike of pills, fear of long-term toxicity, stigma, felt healthy, did not wish to accept one had HIV, and medication selling. Peer-recruited participants differed from their peers in a number of respects: they were significantly more likely to report the following reasons for discontinuation than the clinic-recruited cohort: losing housing, life circumstances changed, substance use, changed their minds, and not being ready.

\section{MULTI-LEVEL BARRIERS TO ART}

\section{Individual/attitudinal-level factors}

Participants answered an average of $68.5 \%$ of items correctly, with no differences between cohorts (9.55 items correct on the
Table 2 | Reasons for ART discontinuation.

\begin{tabular}{|c|c|c|c|c|}
\hline & $\begin{array}{l}\text { Clinic } \\
(N=14) \\
(\%)\end{array}$ & $\begin{array}{l}\text { Peer- } \\
\text { referred } \\
(N=37)(\%)\end{array}$ & $\begin{array}{l}\text { Total } \\
(N=51) \\
(\%)\end{array}$ & $\boldsymbol{P}$ \\
\hline Difficulties with adherence & 28.6 & 54.1 & 47.1 & \\
\hline Side effects & 50.0 & 75.7 & 68.6 & \\
\hline Lost housing & 0.0 & 24.3 & 17.7 & * \\
\hline Provider told me to stop & 21.4 & 13.5 & 15.7 & \\
\hline Friends or family told me to stop & 7.1 & 5.4 & 5.9 & \\
\hline Problems getting prescription filled & 0.0 & 10.8 & 7.8 & \\
\hline Life circumstances changed & 7.1 & 73.0 & 54.9 & ** \\
\hline Substance use got in the way & 14.3 & 56.8 & 45.1 & * \\
\hline Changed my mind & 28.6 & 75.0 & 62.0 & ** \\
\hline Was not ready & 14.3 & 48.7 & 39.2 & * \\
\hline Other reason & 78.6 & 43.2 & 53.0 & * \\
\hline
\end{tabular}

Comparisons made by Fisher's Exact test. Data were missing for the following variables: items 1-8, 10, and 11 (3); item 9 (4). ${ }^{* *} p \geq 0.01$ level, ${ }^{*} p \geq 0.05$ level.

knowledge scale, $\mathrm{SD}=3.02$ items) as shown in Table 3. Levels of general, HIV, and health care provider mistrust were moderate with no difference between cohorts. Mean scores were 2.08 $(\mathrm{SD}=0.66), 2.36(0.65)$, and $2.48(0.7)$, respectively, corresponding to "neutral" on the five-point scale. Self-efficacy scores indicated that participants' views on their abilities to manage ART were neutral (mean 6.52 on $1-10$ scale, $S D=2.13$ ), with no cohort 


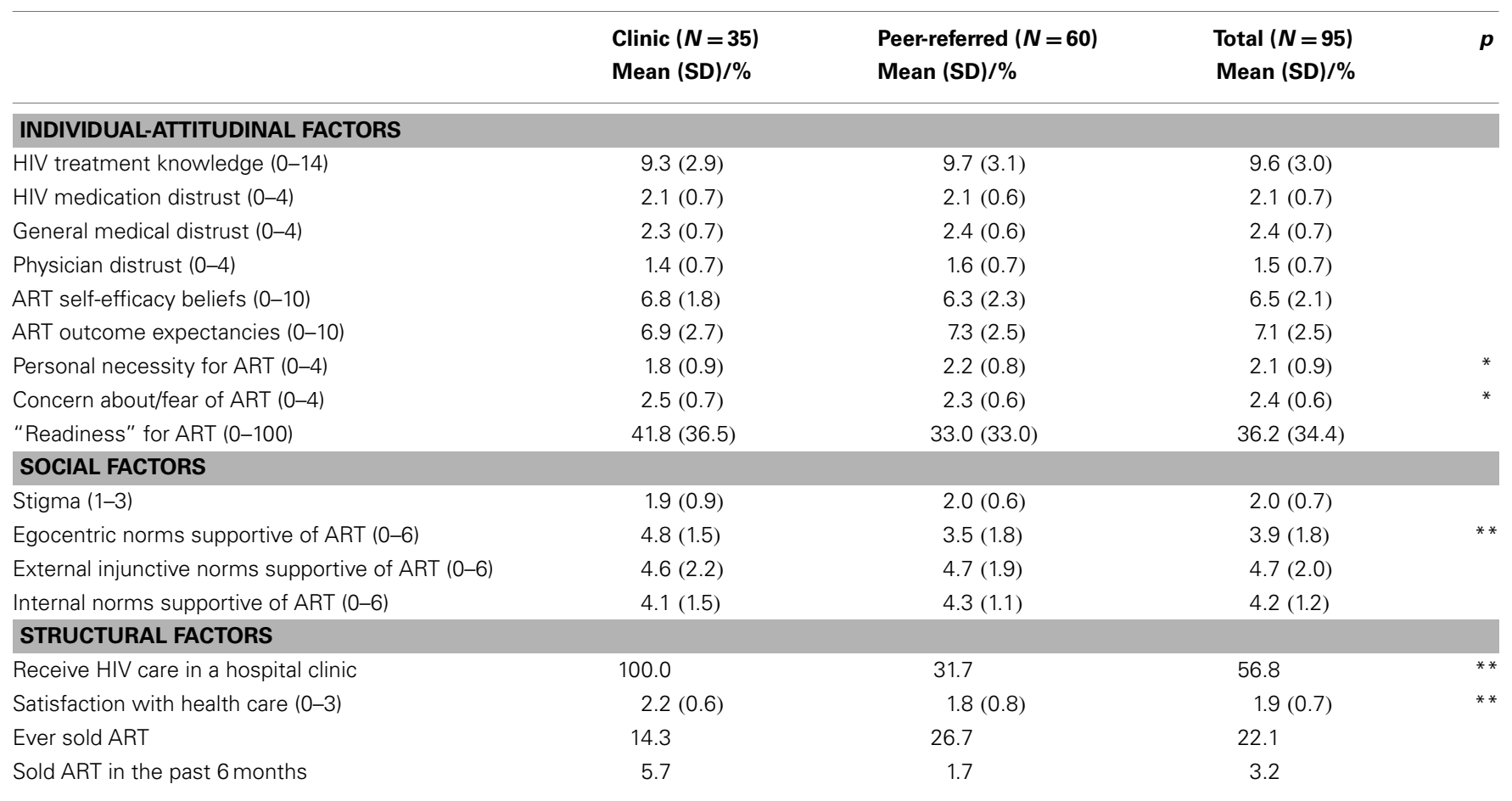

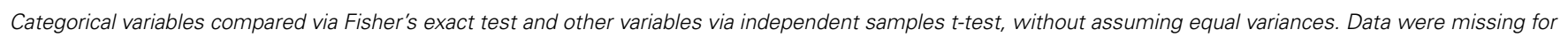
the following variables: ART readiness (3); egocentric norms (8); external norms (4); internal norms (6); and client satisfaction (7). ** $p \geq 0.01$ level, * $p \geq 0.05$ level.

differences. Similarly, outcome expectancies, that is, whether ART is beneficial, were in the positive range for both cohorts (mean $=7.12$ on a $1-10$ scale, $\mathrm{SD}=2.53)$. Personal necessity for ART was moderate (mean $=2.08$ on a $0-4$ scale which corresponds to an answer of "neutral," $\mathrm{SD}=0.88)$. Concern about/fear of ART was also moderate (mean $=2.36$ on a $0-4$ scale which corresponds to an answer of "neutral," SD=0.63). "Readiness" to take ART was modest for both cohorts, with a mean score of 36.23 ( $\mathrm{SD}=34.38$ ). The two cohorts were similar to each other on these individual/attitudinal factors as shown in Table 3 with two exceptions: the peer-referred cohort reported significantly higher personal necessity for ART, but lower concern about/fear of ART.

\section{Social-level influences}

Both cohorts reported similar concerns about stigma as a barrier to $\operatorname{ART}(X=1.99$ on a $1-3$ scale; $\mathrm{SD}=0.72)$. Perceived social norms (egocentric, external, and internal) were also in the neutral range (3.9-4.7 on 0-6 scale). Peer-recruited participants had significantly more negative egocentric norms (suggesting that they view fewer of their peers as favorable toward ART), but did not differ on external or internal norms compared to the clinic-recruited cohort.

\section{Structural-level influences}

About half received HIV care in a hospital-based clinic: all of those in the clinic-recruited cohort (as expected) and $31.7 \%$ of the peerrecruited cohort. Satisfaction with care tended to be satisfactory $(X=1.94$ on a $0-3$ scale, $\mathrm{SD}=0.7)$ but the peer-recruited cohort reported lower satisfaction compared to the clinic cohort. A total of $22.1 \%$ had ever sold medication in the past across the two cohorts.

\section{DIFFERENCES BETWEEN THOSE WHO HAVE DISCONTINUED ART AND THOSE WHO HAVE NEVER TAKEN ART (ART NAÏVE)}

Compared to those who have never taken ART (that is, ART naïve), PLHA who had discontinued ART tended to be significantly older $[$ mean $=49.9(\mathrm{SD}=8.0)$ years vs. $45.5(\mathrm{SD}=9.4)$ years, $p \leq 0.05]$; had lived with HIV longer [ mean $=16.9(\mathrm{SD}=7.6)$ years vs. 11.6 $(\mathrm{SD}=9.3)$ years, $p \leq 0.01]$; had higher levels of HIV knowledge $[$ mean $=10.4(\mathrm{SD}=2.5)$ vs. $8.4(\mathrm{SD}=3.3)]$; had lower levels of concern about ART $[$ mean $=2.1(\mathrm{SD}=0.6)$ vs. $2.7(\mathrm{SD}=0.5)$, $p<0.001$ ]; and lower levels of perceived stigma $[$ mean $=1.9$ $(\mathrm{SD}=0.7)$ vs. $2.2(\mathrm{SD}=0.7), p<0.05]$. The cohorts were similar to each other on remaining health, putative barriers to ART, and whether care was received in a hospital clinic or not. (Data not shown on a table for parsimony.)

\section{FACTORS ASSOCIATED WITH READINESS TO INITIATE ART}

As noted above (see Individual/attitudinal-level factors), readiness for ART was low, although there was great variability. In bivariate analyses, readiness for ART was not associated with cohort (clinic vs. peer) or any socio-demographic or health/health history variable. Instead, a number of individual/attitudinal and sociallevel factors were predictive. Physician mistrust $(B=-10.4)$ was negatively associated with readiness for ART at a statistically significant level, while self-efficacy beliefs ( $B=5.5$ ), positive outcome expectancies $(B=6.3)$, favorable beliefs about the personal necessity of ART $(B=17.5)$, and positive internal norms $(B=7.9)$ were 
Table 4 | Correlations among variables associated with ART readiness.

\begin{tabular}{|c|c|c|c|c|c|c|}
\hline & 1 & 2 & 3 & 4 & 5 & 6 \\
\hline $\begin{array}{l}\text { ART readiness } \\
(0-100)\end{array}$ & 1.00 & & & & & \\
\hline $\begin{array}{l}\text { Physician mistrust } \\
(0-4)\end{array}$ & $-0.22^{*}$ & 1.00 & & & & \\
\hline $\begin{array}{l}\text { ART self-efficacy } \\
\text { beliefs (0-10) }\end{array}$ & $0.34 * *$ & $-0.24^{*}$ & 1.00 & & & \\
\hline $\begin{array}{l}\text { ART outcome } \\
\text { expectancies (0-10) }\end{array}$ & $0.48^{* *}$ & $-0.33^{* *}$ & $0.36^{* *}$ & 1.00 & & \\
\hline $\begin{array}{l}\text { Personal necessity } \\
\text { for ART (0-4) }\end{array}$ & $0.46^{* *}$ & -0.20 & 0.15 & $0.69 * *$ & 1.00 & \\
\hline $\begin{array}{l}\text { Internal norms in } \\
\text { support of ART (0-6) }\end{array}$ & $0.30 * *$ & $-0.26^{*}$ & $0.28^{* *}$ & $0.51 * *$ & $0.50^{* *}$ & 1.00 \\
\hline
\end{tabular}

${ }^{*} p<0.05 ;{ }^{*} p<0.01$.

positively associated with readiness for ART. In Table 4, we present a correlation matrix of the variables found to be associated with readiness for ART. Correlations with ART readiness show medium to large effect sizes (73) and relationships are in the expected direction. In a multiple regression of ART readiness on the five variables with a significant bivariate association, only ART selfefficacy $(B=3.6)$ and personal necessity beliefs $(B=11.54)$ had significant unique associations with ART readiness.

\section{DISCUSSION}

The present study provides a detailed exploration of a vulnerable and hard-to-reach population, PLHA-NOA, and extends past research on PLHA-NOA to include those not embedded in hospital clinic settings. Indeed, diverse recruitment and engagement approaches are necessary for this population, given that at least half of PLHA are estimated to not engage in HIV care at the recommended frequency (3). We focused on African-American and Latino/Hispanic individuals in the present study because they comprise the majority of PLHA and experience a unique set of barriers to ART, partly rooted in culture. Indeed, understanding these barriers can inform efficient, effective, and culturally targeted interventions (15).

\section{FEASIBILITY OF REACHING PLHA-NOA AND LESSONS LEARNED}

Contrary to expectations, we found that it was challenging to recruit PLHA-NOA in clinic settings in the context of this study, but more feasible to do so using a peer-recruitment method. Several factors impeded recruitment in the hospital HIV clinics. First, most PLHA in these settings (>95\%) were taking ART, highlighting the success of these high-quality care settings in engaging patients and bringing them on ART in a timely fashion. Yet among those in clinics not on ART, patterns of infrequent attendance at medical care appointments greatly reduced their chances of participation, in part because providers were unable to confirm the patient's appropriateness for the study and because they did not present for recruitment. Further, when they did present for recruitment, these PLHA were often disinterested in discussing ART use, in many cases, expressing fear of and anxiety related to doing so. This suggests that novel strategies to engage wary patients are needed. Peer-driven interventions may be one promising approach. In peer-driven intervention, the initial contact is made by a peer rather than a study or clinic staff member $(74,75)$. This can foster engagement because peers tend to have a high level of credibility $(74,75)$. Study findings also suggest that self-selection and/or structural barriers reduce the numbers of PLHA with the most serious barriers to ART in clinic settings; these individuals may feel more comfortable in non-medical community-based settings, and non-HIV settings such as harm reduction organizations. The present study also provides important information on whether PLHA-NOA are socially networked with each other. The rapid rate of peer-recruitment suggests that large numbers of them are socially networked, which provides the basis for future studies of this population using social network recruitment approaches. Our study findings further suggest that clinic settings can draw on outreach approaches to engage PLHA-NOA in HIV care at appropriate levels and address barriers to ART.

The present study was consistent with existing literature on hospital clinic vs. community-based settings in some respects (49, 50): PLHA-NOA recruited from the clinics tended to have better health status indicators, even when not taking ART. Yet perhaps in contrast to this past literature, those in non-clinic settings were presented to the study in later stages of HIV disease (although we do not know when they first engaged with the health care setting). Overall, the present study indicates that PLHA recruited through peers, most of whom are not embedded in HIV hospital clinics, are farther along in the course of their HIV disease and have greater contextual risk factors than those in clinics.

We found that an in-depth screening process fostered engagement with the study and, overall, more accurate reporting of ART status. This study component can be retained in the future research. Yet we also found it challenging to confirm medical information from the providers of a substantial number of the peer-recruited cohort, mainly because they were poorly engaged in care. Yet confirmation of HIV health status (CD4, viral load) and ART status (taking vs. not taking) is vital to studies such as these. Indeed, PLHA-NOA commonly report that communication with providers is challenging (76). It is possible that a small number of participants in the present study were taking ART but did not report it to the study in order to enroll. Future studies can consider evaluating CD4 and viral load directly (that is, not relying on the medical record), and recent ART use can be assessed through hair samples (77), to more definitely assess HIV indicators and recent ART use patterns.

\section{REASONS FOR ART DISCONTINUATION}

Among those who had taken ART in the past, participants tended to discontinue their regimens for reasons that appear largely preventable or addressable. Participants did not report difficulties obtaining ART or ART prescription refills, highlighting the strength of the local HIV care system in proving patients with access to ART. Instead, contextual changes (e.g., life circumstances changed, lost housing), substance use, and factors suggesting a low level of readiness for ART (e.g., changed my mind, was not ready) 
contributed to ART discontinuation, particularly among those in the peer-recruited cohorts. This suggests that interventions and programs in clinical settings to increase readiness for ART may also promote sustained ART use (78). Side effects were the single most common reason for discontinuation, consistent with past research $(79,80)$. Yet participants can be prepared for side effects through interventions to improve coping skills for self-management (81) or training on mindfulness based stress reduction (82). Participants who initiated ART some time ago may not realize that the tolerability of regimens has improved, and patient education on the side effect profiles of newer regimens may boost ART uptake (83). Yet PLHA from racial/ethnic minority backgrounds, particularly older PLHA, vividly recall the early days of the HIV epidemic when AZT (Zidovudine) was given in high doses, resulting in side effects including anemia, neutropenia, hepatotoxicity, and myopathy (84). Thus for PLHA from racial/ethnic minority backgrounds, an understanding of ART side effects may be interpreted through a filter of suspicion and medical distrust that is more common among people from racial/ethnic minority backgrounds than Whites, as we have described above (see Introduction) (20). This suggests that interventions to increase ART uptake acknowledge this cultural history and, importantly, address the emotions associated with ART use, particularly fear, in addition to providing health education and fostering adherence skills. Indeed, the role of fear of ART in the problem of PLHA-NOA cannot be over-emphasized $(51,85)$. In future research, we will use quantitative and qualitative research to better understand the issue of side effects, including how PLHA learn about side effects, which side effects cause the greatest concerns, and what types of intervention approaches can help PLHA manage their fear of side effects and the side effects themselves.

\section{MULTI-LEVEL BARRIERS TO ART}

An understanding of barriers to ART can inform the design of programs to improve ART uptake with high adherence. The literature suggests that PLHA-NOA have low levels of HIV knowledge and largely negative attitudes toward ART. Although our ability to interpret study data is somewhat limited by the lack of published norms, findings suggest that knowledge of HIV treatment was at least adequate (average 69\% items correct), albeit with room for improvement, and attitudes toward ART ranged from somewhat negative to neutral. As might be expected in a sample of PLHANOA, readiness to initiate ART was low [mean $36.2(\mathrm{SD}=34.4)$ on a $0-100$ point scale], but with substantial variability. Overall, participants in the two cohorts evidenced similar rates of barriers to ART, although those in the peer-recruited cohort reported greater perceived need for ART, perhaps consistent with their inferior health status and lower rates of concern about/fear of ART, compared to those recruited from clinics.

\section{FACTORS ASSOCIATED WITH READINESS TO INITIATE ART}

Readiness to initiate ART has been found in a number studies to predict treatment outcomes and adherence, and may be an important target for interventions to improve ART uptake. We did not find that socio-demographic or health factors were associated with readiness in this sample. A number of attitudes and beliefs were associated with greater readiness, including higher levels of trust in one's physician, self-efficacy, outcome expectancies, perceived personal need for ART, and positive perceived internal norms (how one feels about others taking ART). This suggests that attitudes toward ART are complex and multifaceted, and include individual and social aspects, and that these various aspects of ART beliefs must be considered together to improve readiness for ART and ART uptake. Horne and colleagues (86) found that uptake of ART was associated with perceptions of personal necessity and concerns about potential adverse effects, and these factors predicted subsequent adherence, independent of clinical variables and depression (86). The present study suggests a number of other social-cognitive factors that may influence these behaviors. Counseling approaches such as motivational interviewing are useful to "unpack" complex and ambivalent attitudes, and thereby enhance intrinsic motivation for health behavior change (54).

\section{THOSE WHO HAVE NEVER TAKEN ART PREVIOUSLY (TREATMENT NAÏVE)}

We found that PLHA who had never taken ART in the past, called "treatment naïve PLHA," differ from those with past ART experience. These treatment naïve PLHA tended to present with a pattern of more serious barriers to ART than their ART-experienced peers, including being less knowledgeable about ART, and evidencing greater fears of ART and of ART-related stigma. Future intervention efforts can take into consideration that younger PLHA and those who have lived with HIV for shorter periods of time may require more support in order to initiate and benefit from ART, in comparison to their peers who have had more time to adapt to their HIV diagnoses and gain knowledge about ART. Yet we do not know at present whether treatment naïve PLHA are less likely than their experienced peers to initiate ART, a question which can be explored in the future research.

\section{ART INITIATION CANNOT BE DISENTANGLED FROM ADHERENCE}

The problem of delayed ART initiation cannot be considered separately from that of ART adherence. Despite recent advances in ART regimens' tolerability and efficacy, and potent new technologies to monitor adherence, the problem of fostering long-term adherence to ART remains one of the greatest challenges facing the public health field today $(87,88)$. A large body of literature has examined the effects of social/behavioral interventions to improve ART adherence with respect to medication-taking behavior and clinical outcomes (87-92). A number of promising adherence interventions had emerged in the last decade, evidencing effects on adherence behavior and viral load (93-96). Yet a review by Simoni and colleagues found that while overall adherence interventions increased the chances of high ART adherence compared to controls, the effect on clinical outcomes (viral load in this case) was not statistically significant, and these effects tend to be short-lived (91). Further, many adherence interventions found successful in experimental trials may not be feasible for implementation in community-based settings and real-world clinics (88). In a recent meta-analysis, de Bruin and colleagues found that nonwhite patients had a lower chance of achieving undetectable viral load compared to whites. However, they did not find racial/ethnic differences in adherence success rates. They speculated these viral load differences may have been caused by pre-treatment clinical 
status, or that adherence differences were not found due to a lack of adherence measures with cross-cultural validity (90). Thus efforts to develop behavioral interventions to improve ART initiation can benefit from and build on this rich literature in the domain of ART adherence, with particular attention to non-white PLHA, who may experience the greatest barriers to adherence and/or good clinical outcomes.

\section{LIMITATIONS}

The present study's limitations include a lack of knowledge of the true size and scope of this vulnerable population, as well as the relatively small sample sizes which may have prevented us from detecting differences between cohorts. Further, the convenience sampling approach may limit the generalizability of study findings to other settings. In addition, the low proportion of clinic-recruited PLHA suggests that those enrolled may not be representative of the larger population of PLHA in clinics; they may represent those most willing to consider ART, thus biasing findings toward more favorable outcomes. Moreover, the ability of the present study to examine complex relationships across multiple variables was limited by sample size. Structural equation modeling in larger samples is therefore needed to better understand processes that promote or impede readiness for ART. Last, the present study was exploratory in nature and targeted PLHA able to conduct research activities in English. We will extend future research to mono-lingual Spanish-speaking PLHA, although the size of this population appears small in our local area $(<5 \%$ of PLHA) (97).

\section{IMPLICATIONS FOR FUTURE RESEARCH AND PRACTICE}

To achieve the goals of the National HIV/AIDS Strategy (NHAS), PLHA must initiate ART in a timely fashion, and remain on ART with high adherence through their lives. Studies on the HIV continuum of care indicate that improvements are needed at each stage, and the CDC calls for particular efforts to reduce health disparities by race and ethnicity (3). The present study advances our knowledge of a vulnerable and hard-to-find population of PLHA that is critical to efforts to reduce gaps along the HIV continuum of care. Importantly, the results of this study and recent conceptualizations of the HIV continuum of care in low-resource, international settings (98) strongly suggest that engagement in care and use of ART are not static, but entail ongoing, multi-faceted processes. Future work is needed to articulate a more detailed HIV continuum of care with a focus on intermediate steps between linkage to care, engagement in care, ART initiation, and ART continuation with high adherence, and devise intervention strategies for improving outcomes along this more detailed care continuum.

\section{ACKNOWLEDGMENTS}

We wish to thank the men and women who participated in the study, the Peter Krueger Clinic for Immunological Disorders at Mt. Sinai Beth, Israel Medical Center, Spencer Cox Center for Health at Mt. Sinai St. Luke's-Roosevelt Hospital Center, and Gay Men's Health Crisis for making this study possible. Special thanks to Rob Shiau at Peter Krueger Clinic and Zach Hennessey, MA at Spencer Cox for facilitating study implementation. This work would not have been possible without Kelly Bolger, MA; Isaiah Pickens, Ph.D.;
DeShannon Bowens, MA; Amy Braksmajer, Ph.D.; David Perlman, MD; Victoria Sharp, MD; and the Center for Drug Use and HIV Research (CDUHR; P30 DA011041). The study was supported by the National Institutes of Mental Health (R34MH093352). We particularly wish to acknowledge our Program Officer at the National Institute of Mental Health (NIMH), Program Chief at the NIMH Division of AIDS Research, Michael Stirratt, Ph.D.

\section{REFERENCES}

1. Boyd MA. Improvements in antiretroviral therapy outcomes over calendar time. Curr Opin HIV AIDS (2009) 4(3):194-9. doi:10.1097/COH.0b013e328329fc8d

2. Hanna DB, Buchacz K, Gebo KA, Hessol NA, Horberg MA, Jacobson LP, et al. Trends and disparities in antiretroviral therapy initiation and virologic suppression among newly treatment-eligible HIV-infected individuals in North America, 2001-2009. Clin Infect Dis (2013) 56(8):1174-82. doi:10.1093/cid/cit003

3. Hall HI, Frazier EL, Rhodes P, Holtgrave DR, Furlow-Parmley C, Tang T, et al. Differences in human immunodeficiency virus care and treatment among subpopulations in the United States. JAMA Intern Med (2013) 173(14):1337-44. doi:10.1001/jamainternmed.2013.6841

4. Wong MD, Cunningham WE, Shapiro MF, Andersen RM, Cleary PD, Duan N, et al. Disparities in HIV treatment and physician attitudes about delaying protease inhibitors for nonadherent patients. J Gen Intern Med (2004) 19(4):366-74. doi:10.1111/j.1525-1497.2004.30429.x

5. Gardner EM, McLees MP, Steiner JF, Del Rio C, Burman WJ. The spectrum of engagement in HIV care and its relevance to test-and-treat strategies for prevention of HIV infection. Clin Infect Dis (2011) 52(6):793-800. doi:10.1093/cid/ciq243

6. Horstmann E, Brown J, Islam F, Buck J, Agins BD. Retaining HIV-infected patients in care: where are we? Where do we go from here? Clin Infect Dis (2010) 50(5):752-61. doi:10.1086/649933

7. Mugavero MJ, Amico KR, Horn T, Thompson MA. The state of engagement in HIV care in the United States: from cascade to continuum to control. Clin Infect Dis (2013) 57(8):1164-71. doi:10.1093/cid/cit420

8. Losina E, Schackman BR, Sadownik SN, Gebo KA, Walensky RP, Chiosi JJ, et al. Racial and sex disparities in life expectancy losses among HIV-infected persons in the United States: impact of risk behavior, late initiation, and early discontinuation of antiretroviral therapy. Clin Infect Dis (2009) 49(10):1570-8. doi:10.1086/644772

9. Stricker SM, Fox KA, Baggaley R, Negussie E, de Pee S, Grede N, et al. Retention in care and adherence to ART are critical elements of HIV care interventions. AIDS Behav (2013). doi:10.1007/s10461-013-0598-6

10. O'Brien ME, Clark RA, Besch CL, Myers L, Kissinger P. Patterns and correlates of discontinuation of the initial HAART regimen in an urban outpatient cohort. J Acquir Immune Defic Syndr (2003) 34(4):407-14. doi:10.1097/ 00126334-200312010-00008

11. Yuan Y, L'Italien G, Mukherjee J, Iloeje UH. Determinants of discontinuation of initial highly active antiretroviral therapy regimens in a US HIV-infected patient cohort. HIV Med (2006) 7(3):156-62. doi:10.1111/j.1468-1293.2006.00355.x

12. Kempf MC, Pisu M, Dumcheva A, Westfall AO, Kilby JM, Saag MS. Gender differences in discontinuation of antiretroviral treatment regimens. J Acquir Immune Defic Syndr (2009) 52(3):336-41. doi:10.1097/QAI.0b013e3181b628be

13. Whiteside YO, Cohen SM, Bradley H, Skarbinski J, Hall HI, Lansky A. Progress along the continuum of HIV care among blacks with diagnosed HIV-United States, 2010. MMWR Morb Mortal Wkly Rep (2014) 63(5):85-9.

14. Kreuter MW, Lukwago SN, Bucholtz RD, Clark EM, Sanders-Thompson V. Achieving cultural appropriateness in health promotion programs: targeted and tailored approaches. Health Educ Behav (2003) 30(2):133-46. doi:10.1177/ 1090198102251021

15. Netto G, Bhopal R, Lederle N, Khatoon J, Jackson A. How can health promotion interventions be adapted for minority ethnic communities? Five principles for guiding the development of behavioural interventions. Health Promot Int (2010) 25(2):248-57. doi:10.1093/heapro/daq012

16. Flay BR, Snyder F, Petraitis J. The theory of triadic influence. In: DiClimente RJ, Kegler MC, Crosby RA, editors. Emerging Theories in Health Promotion Practice and Research. New York: Jossey-Bass (2009). p. 451-510.

17. Schönnesson LN, Williams ML, Ross MW, Diamond PM, Keel B. Three types of adherence to HIV antiretroviral therapy and their association with AIDS 
diagnosis, medication side-effects, beliefs about antiretroviral therapy, and beliefs about HIV disease. Int J STD AIDS (2007) 18(6):369-73. doi:10.1258/ 095646207781024757

18. Johnson MO, Chesney MA, Neilands TB, Dilworth SE, Remien RH, Weinhardt LS, et al. Disparities in reported reasons for not initiating or stopping antiretroviral treatment among a diverse sample of persons living with HIV. J Gen Intern Med (2009) 24(2):247-51. doi:10.1007/s11606-008-0854-z

19. Washington HA. Medical Apartheid: The Dark History of Medical Experimentation on Black Americans from Colonial Times to the Present. New York: Random House LLC (2006).

20. Thomas SB, Quinn SC. The Tuskegee Syphilis study, 1932 to 1972: implications for HIV education and AIDS risk education programs in the black community. Am J Public Health (1991) 81(11):1498-505. doi:10.2105/AJPH.81.11.1498

21. Ford CL, Airhihenbuwa CO. Critical race theory, race equity, and public health: toward antiracism praxis. Am J Public Health (2010) 100(Suppl 1):S30. doi:10.2105/AJPH.2009.171058

22. Bogart LM. Relationship of discrimination and HIV conspiracy beliefs to medication non-adherence among HIV-positive African American men. Presented at the CDUHR AIDS Seminar, New York (2011).

23. Beer L, Fagan JL, Garland P, Valverde EE, Bolden B, Brady KA, et al. Medicationrelated barriers to entering HIV care. AIDS Patient Care STDS (2012) 26(4):214-21. doi:10.1089/apc.2011.0407

24. Kerr T, Palepu A, Barness G, Walsh J, Hogg R, Montaner J, et al. Psychosocial determinants of adherence to highly active antiretroviral therapy among injection drug users in Vancouver. Antivir Ther (2004) 9(3):407-14.

25. Maisels L, Steinberg J, Tobias C. An investigation of why eligible patients do not receive HAART. AIDS Patient Care STDS (2001) 15(4):185-91. doi:10.1089/ 10872910151133701

26. Kremer H, Bader A, O'Cleirigh C, Bierhoff HW, Brockmeyer NH. The decision to forgo antiretroviral therapy in people living with HIV-compliance as paternalism or partnership? Eur J Med Res (2004) 9(2):61-70.

27. Pence BW, Ostermann J, Kumar V, Whetten K, Thielman N, Mugavero MJ. The influence of psychosocial characteristics and race/ethnicity on the use, duration, and success of antiretroviral therapy. J Acquir Immune Defic Syndr (2008) 47(2):194-201. doi:10.1097/QAI.0b013e31815ace7e

28. Horne R, Buick D, Fisher M, Leake H, Cooper V, Weinman J. Doubts about necessity and concerns about adverse effects: identifying the types of beliefs that are associated with non-adherence to HAART. Int J STD AIDS (2004) 15(1):38-44. doi:10.1258/095646204322637245

29. Sodergard B, Hofer S, Halvarsson M, Sonnerborg A, Tully MP, Lindblad AK. A structural equation modeling approach to the concepts of adherence and readiness in antiretroviral treatment. Patient Educ Couns (2007) 67(1-2):108-16. doi:10.1016/j.pec.2007.02.010

30. Grimes RM, Grimes DE. Readiness: the state of the science (or the lack thereof). Curr HIV/AIDS Rep (2010) 7(4):245-52. doi:10.1007/s11904-010-0056-2

31. Gwadz MV, Colon P, Ritchie AS, Leonard NR, Cleland CM, Riedel M, et al. Increasing and supporting the participation of persons of color living with HIV/AIDS in AIDS clinical trials. Curr HIV/AIDS Rep (2010) 7(4):194-200. doi:10.1007/s11904-010-0055-3

32. Gwadz MV, Cylar K, Leonard NR, Riedel M, Herzog N, Arredondo GN, et al. An exploratory behavioral intervention trial to improve rates of screening for AIDS clinical trials among racial/ethnic minority and female persons living with HIV/AIDS. AIDS Behav (2010) 14(3):639-48. doi:10.1007/s10461-009-9539-9

33. Johnston SS, Juday T, Seekins D, Hebden T, Fulcher N, Farr AM, et al. Patterns and correlates of linkage to appropriate HIV care after HIV diagnosis in the US medicaid population. Sex Transm Dis (2013) 40(1):18-25. doi:10.1097/OLQ.0b013e3182782014

34. Agwu AL, Neptune A, Voss C, Yehia B, Rutstein R. CD4 counts of nonperinatally HIV-infected youth and young adults presenting for HIV care between 2002 and 2010. JAMA Pediatr (2014) 168(4):381-3. doi:10.1001/jamapediatrics. 2013.4531

35. Mayer KH. Introduction: linkage, engagement, and retention in HIV care: essential for optimal individual-and community-level outcomes in the era of highly active antiretroviral therapy. Clin Infect Dis (2011) 52(Suppl 2):S205-7. doi:10.1093/cid/ciq043

36. Tegger MK, Crane HM, Tapia KA, Uldall KK, Holte SE, Kitahata MM. The effect of mental illness, substance use, and treatment for depression on the initiation of highly active antiretroviral therapy among HIV-infected individuals. AIDS Patient Care STDS (2008) 22(3):233-43. doi:10.1089/apc.2007.0092
37. Metsch LR, Pereyra M, Brewer TH. Use of HIV health care in HIV-seropositive crack cocaine smokers and other active drug users. J Subst Abuse (2001) 13(12):155-67. doi:10.1016/S0899-3289(01)00064-5

38. Anastos K, Schneider MF, Gange SJ, Minkoff H, Greenblatt RM, Feldman J, et al. The association of race, sociodemographic, and behavioral characteristics with response to highly active antiretroviral therapy in women. JAcquir Immune Defic Syndr (2005) 39(5):537-44.

39. Kalichman SC, Rompa D, Cage M, DiFonzo K, Simpson D, Austin J, et al. Effectiveness of an intervention to reduce HIV transmission risks in HIVpositive people. Am J Prev Med (2001) 21(2):84-92. doi:10.1016/S07493797(01)00324-5

40. Soto TA, Bell J, Pillen M. HIV/AIDS Treatment Adherence, Health Outcomes Cost Study Group. Literature on integrated HIV care: a review. AIDS Care (2004) 16(supl 1):43-55. doi:10.1080/09540120412331315295

41. Stall R, Hoff C, Coates TJ, Paul J, Phillips KA, Ekstrand M, et al. Decisions to get HIV tested and to accept antiretroviral therapies among gay/bisexual men: implications for secondary prevention efforts. J Acquir Immune Defic Syndr (1996) 11(2):151-60.

42. Stone VE, Clarke J, Lovell J, Steger KA, Hirschhorn LR, Boswell S, et al. HIV/AIDS patients' perspectives on adhering to regimens containing protease inhibitors. J Gen Intern Med (1998) 13(9):586-93. doi:10.1046/j.1525-1497. 1998.00180.x

43. Panel on Antiretroviral Guidelines for Adults and Adolescents. Guidelines for the Use of Antiretroviral Agents in HIV-1-Infected Adults and Adolescents. (2013). Available from: http://aidsinfo.nih.gov/ContentFiles/AdultandAdolescentGL. pdf

44. Meyer JP, Althoff AL, Altice FL. Optimizing care for HIV-infected people who use drugs: evidence-based approaches to overcoming healthcare disparities. Clin Infect Dis (2013) 57(9):1309-17. doi:10.1093/cid/cit427

45. Kremer H, Ironson G. To tell or not to tell: why people with HIV share or don't share with their physicians whether they are taking their medications as prescribed. AIDS Care (2006) 18(5):520-8. doi:10.1080/09540120600766020

46. Sumartojo E. Structural factors in HIV prevention: concepts, examples, and implications for research. AIDS (2000) 14(Suppl 1):S3-10. doi:10.1097/ 00002030-200006001-00002

47. Coetzee B, Kagee A. The development of an inventory to assess the structural barriers to clinic attendance and pill-taking amongst users of antiretroviral therapy. AIDS Behav (2013) 17(1):319-28. doi:10.1007/s10461-012-0374-z

48. Messer LC, Quinlivan EB, Parnell H, Roytburd K, Adimora AA, Bowditch N, et al. Barriers and facilitators to testing, treatment entry, and engagement in care by HIV-positive women of color. AIDS Patient Care STDS (2013) 27(7):398-407. doi:10.1089/apc.2012.0435

49. Chu C, Umanski G, Blank A, Grossberg R, Selwyn PA. HIV-infected patients and treatment outcomes: an equivalence study of community-located, primary care-based HIV treatment vs. hospital-based specialty care in the Bronx, New York. AIDS Care (2010) 22(12):1522-9. doi:10.1080/09540121. 2010.484456

50. Schranz A, Brady K, Keller S, Momplaisir F, Metlay J, Yehia BR. Outcomes Differ for HIV-Infected Patients Receiving Care at Hospital vs. Community-Based Clinics. Abstract presented at IDWeek; 2013 Oct 2-6; San Francisco, CA (2013).

51. Roberts KJ, Mann T. Barriers to antiretroviral medication adherence in HIV-infected women. AIDS Care (2000) 12(4):377-86. doi:10.1080/ 09540120050123774

52. Magnani R, Sabin K, Saidel T, Heckathorn D. Review of sampling hard-to-reach and hidden populations for HIV surveillance. AIDS (2005) 19(Suppl 2):S67-72. doi:10.1097/01.aids.0000172879.20628.e1

53. Deering KN, Shannon K, Sinclair H, Parsad D, Gilbert E, Tyndall MW. Piloting a peer-driven intervention model to increase access and adherence to antiretroviral therapy and HIV care among street-entrenched HIV-positive women in Vancouver. AIDS Patient Care STDS (2009) 23(8):603-9. doi:10.1089/apc.2009. 0022

54. Miller WR, Rollnick S. Motivational Interviewing: Helping People Change. New York: Guilford Press (2012).

55. National Institute on Drug Abuse. Seek, Test, Treat and Retain for Vulnerable Populations: Data Harmonization Measure (Demographics Measure). (2012). Available from: http://www.drugabuse.gov/sites/default/files/sttrfiles/ DemographicsV.pdf

56. Shapiro MF, Morton SC, McCaffrey DF, Senterfitt JW, Fleishman JA, Perlman JF, et al. Variations in the care of HIV-infected adults in the United States: results 
from the HIV cost and services utilization study. JAMA (1999) 281(24):2305-15. doi:10.1001/jama.281.24.2305

57. Justice AC, Holmes W, Gifford AL, Rabeneck L, Zackin R, Sinclair G, et al. Development and validation of a self-completed HIV symptom index. JClin Epidemiol (2001) 54(Suppl 1):S77-90. doi:10.1016/S0895-4356(01)00449-8

58. HIV/AIDS Treatment Adherence Health Outcomes Cost Study Group. The HIV/AIDS treatment adherence, health outcomes, and cost study: conceptual foundations and overview. AIDS Care (2004) 16(supl 1):6-21. doi:10.1080/ 09540120412331315312

59. Balfour L, Kowal J, Tasca G, Cooper C, Angel J, Macpherson P, et al. Development and psychometric validation of the HIV Treatment Knowledge Scale. AIDS Care (2007) 19(9):1141-8. doi:10.1080/09540120701352241

60. LaVeist TA, Isaac LA, Williams KP. Mistrust of Health Care Organizations is associated with underutilization of health services. Health Serv Res (2009) 44(6):2093-105. doi:10.1111/j.1475-6773.2009.01017.x

61. Altice FL, Mostashari F, Friedland GH. Trust and the acceptance of and adherence to antiretroviral therapy. J Acquir Immune Defic Syndr (2001) 28(1):47-58. doi:10.1097/00042560-200109010-00008

62. Anderson LA, Dedrick RF. Development of the trust in physician scale: a measure to assess interpersonal trust in patient-physician relationships. Psychol Rep (1990) 67(3f):1091-100. doi:10.2466/PR0.67.7.1091-1100

63. Erlen JA, Cha ES, Kim KH, Caruthers D, Sereika SM. The HIV medication taking self-efficacy scale: psychometric evaluation. J Adv Nurs (2010) 66(11):2560-72. doi:10.1111/j.1365-2648.2010.05400.x

64. Horne R, Weinman J, Hankins M. The beliefs about medicines questionnaire: the development and evaluation of a new method for assessing the cognitive representation of medication. Psychol Health (1999) 14(1):1-24. doi:10.1080/08870449908407311

65. Rollnick S. Readiness, importance, and confidence: critical conditions of change in treatment. In: Heather WRMN, editor. Treating Addictive Behaviors (2nd Ed.). Applied Clinical Psychology. New York, NY: Plenum Press (1998). p. 49-60.

66. Rintamaki LS, Davis TC, Skripkauskas S, Bennett CL, Wolf MS. Social stigma concerns and HIV medication adherence. AIDS Patient Care STDS (2006) 20(5):359-68. doi:10.1089/apc.2006.20.359

67. Flom PL, Friedman SR, Kottiri BJ, Neaigus A, Curtis R. Recalled adolescent peer norms towards drug use in young adulthood in a low-income, minority urban neighborhood. J Drug Issues (2001) 31(2):425-44.

68. Huba GJ, Melchior LA; Staff of the measurement Group; HRSA/HAB's SPNS Cooperative Agreement Steering Committee. Module 11: Client Satisfaction Survey. Culver City, CA: The Measurement Group (1997). Available from: www.themeasurementgroup.com

69. van Buuren S. Multiple imputation of discrete and continuous data by fully conditional specification. Stat Methods Med Res (2007) 16(3):219-42. doi:10. 1177/0962280206074463

70. R Core Team. R: A Language and Environment for Statistical Computing. Vienna: R Foundation for Statistical Computing (2014).

71. van Buuren S, Groothuis-Oudshoorn K. mice: Multivariate Imputation by Chained Equations in R. J Stat Softw (2011) 45(3):1-67.

72. Rubin DB. Multiple Imputation for Nonresponse in Surveys. New York: John Wiley \& Sons (1987).

73. Cohen J. Statistical Power Analysis for the Behavioral Sciences. Hillsdale, NJ: Lawrence (1988).

74. Gwadz MVP, Leonard NRP, Cleland CMP, Riedel MP, Banfield A, Mildvan DMD. The effect of peer-driven intervention on rates of screening for AIDS clinical trials among African Americans and Hispanics. Am J Public Health (2011) 101(6):1096-102. doi:10.2105/AJPH.2010.196048

75. Broadhead RS, Heckathorn DD, Weakliem DL, Anthony DL, Madray H, Mills $\mathrm{RJ}$, et al. Harnessing peer education networks as an instrument for AIDS prevention. Public Health Rep (1998) 113(Suppl 1):42-57.

76. Murphy DA, Roberts KJ, Martin DJ, Marelich W, Hoffman D. Barriers to antiretroviral adherence among HIV-infected adults. AIDS Patient Care STDS (2000) 14(1):47-58. doi:10.1089/108729100318127

77. Gandhi M, Ameli N, Bacchetti P, Anastos K, Gange SJ, Minkoff $\mathrm{H}$, et al. Atazanavir concentration in hair is the strongest predictor of outcomes on antiretroviral therapy. Clin Infect Dis (2011) 52(10):1267-75. doi:10.1093/cid/ cirl31

78. Wagner GJ, Lovely P, Schneider S. Pilot controlled trial of the adherence readiness program: an intervention to assess and sustain HIV antiretroviral adherence readiness. AIDS Behav (2013) 17(9):3059-65. doi:10.1007/s10461013-0550-9

79. Ammassari A, Murri R, Pezzotti P, Trotta MP, Ravasio L, De Longis P, et al. Self-reported symptoms and medication side effects influence adherence to highly active antiretroviral therapy in persons with HIV infection. $J$ Acquir Immune Defic Syndr (2001) 28(5):445-9. doi:10.1097/00126334-20011215000006

80. Hughes AJ, Mattson CL, Scheer S, Beer L, Skarbinski J. Discontinuation of antiretroviral therapy among adults receiving HIV care in the United States. J Acquir Immune Defic Syndr (2014) 66(1):80-9. doi:10.1097/QAI. 0000000000000084

81. Johnson MO, Dilworth SE, Taylor JM, Neilands TB. Improving coping skills for self-management of treatment side effects can reduce antiretroviral medication nonadherence among people living with HIV. Ann Behav Med (2011) 41(1):83-91. doi:10.1007/s12160-010-9230-4

82. Duncan LG, Moskowitz JT, Neilands TB, Dilworth SE, Hecht FM, Johnson MO. Mindfulness-based stress reduction for HIV treatment side effects: a randomized, wait-list controlled trial. J Pain Symptom Manage (2012) 43(2):161-71. doi:10.1016/j.jpainsymman.2011.04.007

83. Hawkins T. Understanding and managing the adverse effects of antiretroviral therapy. Antiviral Res (2010) 85(1):201-9. doi:10.1016/j.antiviral.2009.10.016

84. NAM AIDSMap. Side Effects. (2014). Available from: http://www.aidsmap.com/ Side-effects/page/1730907/

85. Golin C, Isasi F, Bontempi JB, Eng E. Secret pills: HIV-positive patients' experiences taking antiretroviral therapy in North Carolina. AIDS Educ Prev (2002) 14(4):318-29. doi:10.1521/aeap.14.5.318.23870

86. Horne R, Cooper V, Gellaitry G, Date HL, Fisher M. Patients' perceptions of highly active antiretroviral therapy in relation to treatment uptake and adherence: the utility of the necessity-concerns framework. J Acquir Immune Defic Syndr (2007) 45(3):334-41. doi:10.1097/QAI.0b013e31806910e3

87. Simoni JM, Frick PA, Pantalone DW, Turner BJ. Antiretroviral adherence interventions: a review of current literature and ongoing studies. Top HIV Med (2003) 11(6):185-98.

88. Simoni JM, Amico KR, Pearson CR, Malow R. Strategies for promoting adherence to antiretroviral therapy: a review of the literature. Curr Infect Dis Rep (2008) 10(6):515-21. doi:10.1007/s11908-008-0083-y

89. Bain-Brickley D, Butler LM, Kennedy GE, Rutherford GW. Interventions to improve adherence to antiretroviral therapy in children with HIV infection. Cochrane Database Syst Rev (2011) (12):CD009513. doi:10.1002/14651858. CD009513

90. de Bruin M, Viechtbauer W, Schaalma HP, Kok G, Abraham C, Hospers HJ. Standard care impact on effects of highly active antiretroviral therapy adherence interventions: a meta-analysis of randomized controlled trials. Arch Intern Med (2010) 170(3):240-50. doi:10.1001/archinternmed.2009.536

91. Simoni JM, Pearson CR, Pantalone DW, Marks G, Crepaz N. Efficacy of interventions in improving highly active antiretroviral therapy adherence and HIV1 RNA viral load: a meta-analytic review of randomized controlled trials. $J$ Acquir Immune Defic Syndr (2006) 1(43 Suppl 1):S23-35. doi:10.1097/01.qai. 0000248342.05438 .52

92. Reisner SL, Mimiaga MJ, Skeer M, Perkovich B, Johnson CV, Safren SA. A review of HIV antiretroviral adherence and intervention studies among HIV-infected youth. Top HIV Med (2009) 17(1):14-25.

93. de Bruin M, Hospers HJ, van Breukelen GJ, Kok G, Koevoets WM, Prins JM. Electronic monitoring-based counseling to enhance adherence among HIV-infected patients: a randomized controlled trial. Health Psychol (2010) 29(4):421-8. doi:10.1037/a0020335

94. Kurth AE, Spielberg F, Cleland CM, Lambdin B, Bangsberg DR, Frick PA, et al. Computerized counseling reduces HIV-1 viral load and sexual transmission risk: findings from a randomized controlled trial. J Acquir Immune Defic Syndr (2014) 65(5):611-20. doi:10.1097/QAI.0000000000000100

95. Macalino GE, Hogan JW, Mitty JA, Bazerman LB, Delong AK, Loewenthal H, et al. A randomized clinical trial of community-based directly observed therapy as an adherence intervention for HAART among substance users. AIDS (2007) 21(11):1473-7. doi:10.1097/QAD.0b013e32811ebf68

96. Parsons JT, Golub SA, Rosof E, Holder C. Motivational interviewing and cognitive-behavioral intervention to improve HIV medication adherence among hazardous drinkers: a randomized controlled trial. J Acquir Immune Defic Syndr (2007) 46(4):443-50. doi:10.1097/QAI.0b013e318158a461 
97. Jenness SM, Neaigus A, Hagan H, Wendel T, Bonilla G, Colon R, et al. HIV Risk and Prevalence among New York City High-Risk Heterosexuals: Results from the 2010 National HIV Behavioral Surveillance Study. (2010). Available from: http://www.nyc.gov/html/doh/downloads/pdf/dires/nhbshet2_may2011. pdf

98. McNairy ML, Lamb M, Elul B, Abrams E, El-Sadr W. The identifying optimal models of HIV care in Africa study. A new paradigm for evaluating the HIV care cascade. Conference on Retroviruses and Opportunistic Infections, Boston, MA (2014).

Conflict of Interest Statement: The authors declare that the research was conducted in the absence of any commercial or financial relationships that could be construed as a potential conflict of interest.

Received: 26 March 2014; accepted: 29 June 2014; published online: 16 July 2014.
Citation: Gwadz M, Applegate E, Cleland C, Leonard NR, Wolfe H, Salomon N, Belkin M, Riedel M, Banfield A, Sanfilippo L, Wagner A, Mildvan D and The Heart to Heart Collaborative Research Team (2014) HIV-infected individuals who delay, decline, or discontinue antiretroviral therapy: comparing clinic-and peer-recruited cohorts. Front. Public Health 2:81. doi:10.3389/fpubh.2014.00081

This article was submitted to HIV and AIDS, a section of the journal Frontiers in Public Health.

Copyright $(0) 2014$ Gwadz, Applegate, Cleland, Leonard, Wolfe, Salomon, Belkin, Riedel, Banfield, Sanfilippo, Wagner, Mildvan and The Heart to Heart Collaborative Research Team. This is an open-access article distributed under the terms of the Creative Commons Attribution License (CC BY). The use, distribution or reproduction in other forums is permitted, provided the original author(s) or licensor are credited and that the original publication in this journal is cited, in accordance with accepted academic practice. No use, distribution or reproduction is permitted which does not comply with these terms. 